\title{
The Role of Market-Mediated Milestones in Negotiating Adolescent Identity Tensions
}

Jenna M. Drenten

Loyola University Chicago, jdrenten@luc.edu

Follow this and additional works at: https://ecommons.luc.edu/business_facpubs

Part of the Business Commons

\section{Author Manuscript}

This is a pre-publication author manuscript of the final, published article.

\section{Recommended Citation}

Drenten, Jenna M.. The Role of Market-Mediated Milestones in Negotiating Adolescent Identity Tensions. Research in Consumer Behavior: Consumer Culture Theory, 15, : 97-122, 2014. Retrieved from Loyola eCommons, School of Business: Faculty Publications and Other Works,

This Article is brought to you for free and open access by the Faculty Publications and Other Works by Department at Loyola eCommons. It has been accepted for inclusion in School of Business: Faculty Publications and Other Works by an authorized administrator of Loyola eCommons. For more information, please contact ecommons@luc.edu.

\section{c) (i) $९$}

This work is licensed under a Creative Commons Attribution-Noncommercial-No Derivative Works 3.0 License. (c) Emerald Publishing Group 2014 
Drenten, Jenna (2013), "The Role of Market-Mediated Milestones in Negotiating Adolescent Identity Tensions," in Russell W. Belk, Linda Price, and Lisa Peñaloza (Eds.), Research in Consumer Behavior: Consumer Culture Theory, Vol. 15, Bingley, UK: Emerald Group Publishing Limited, 97-122.

Note: This is a preprint version. The final published version of the paper may reflect notable format and content changes.

\title{
THE ROLE OF MARKET-MEDIATED MILESTONES IN NEGOTIATING ADOLESCENT IDENTITY TENSIONS
}

\begin{abstract}
Purpose-This chapter explores the symbolic connections between coming of age liminality and identity-oriented consumption practices in postmodern American culture, specifically among adolescent girls.

Methodology/Approach-Forty-two female participants (ages 20-23) participants were asked to answer the general question of "Who Am I?" through creating identity collages and writing accompanying narrative summaries for each of three discrete life stages: early adolescence (pastself), late adolescence (present-self), and adulthood (future-self). Data were analyzed using a hermeneutical approach.

Findings - Coming of age in postmodern American consumer culture involves negotiating paradoxical identity tensions through consumption-oriented benchmarks, termed "marketmediated milestones." Market-mediated milestones represent achievable criteria by which adolescents solidify their uncertain liminal self-concepts.

Research implications - In contrast to the traditional Van Gennepian conceptualization of rites of passage, market-mediated milestones do not necessarily mark a major transition from one social status to another, nor do they follow clearly defined stages. Market-mediated milestones help adolescents navigate liminality through an organic, nonlinear, and incremental coming of age process.

Practical implications-Rather than traditional cultural institutions (e.g., church, family), the marketplace is becoming the central cultural institution around which adolescent coming of age identity is constructed. As such, organizations have the power to create market-mediated milestones for young people. In doing so, organizations should be mindful of adolescent wellbeing.

Originality/Value-This research marks a turning point in understanding traditional rites of passage in light of postmodern degradation of cultural institutions. The institutions upon which traditional rites of passage are based have changed; therefore, our conceptions of what rites of passage are today should change as well.
\end{abstract}

KEYWORDS: identity development, adolescent consumers, rites of passage 


\section{THE ROLE OF MARKET-MEDIATED MILESTONES IN NEGOTIATING ADOLESCENT IDENTITY TENSIONS}

\section{INTRODUCTION}

In the 1955 classic American film, Rebel Without a Cause, actress Natalie Wood portrays Judy, a tough-talking teenage girl who, much to her parents dismay, is in a fickle state between 'little girl' and 'grown-up'. Her mother attempts to calm Judy's frustrated father by saying, "She'll outgrow it dear. It's just the age. It's just the age when nothing fits." Like Judy, today's modern young girls find themselves in a coming of age period, in which they are wedged between two statuses: child and adult. They have left behind the previous stage, yet they have not reached the new one. Anthropologists coin this transitional experience as liminal, which originates from the Latin term for "threshold" and describes the stage in rites of passage between separation and reincorporation (Turner 1987; van Gennep 1960). Turkle (1998, p. 71) suggests that "liminal moments are times of tension, extreme reactions, and great opportunity."

Adolescence represents the liminal bridge between childhood and adulthood; however, recent studies suggest that the transition is becoming increasingly prolonged (e.g., young people are delaying historically adult-oriented experiences like marriage and parenting), particularly among American teenagers (Arnett 2000, 2004; Arnett and Tanner 2005). The delay in taking on adult identity roles is largely due to the postmodern diminution of shared communal structures (e.g., religious, ethnic; Firat and Shultz 1997), which typically guide coming of age rites of passage (see Van Gennep 1960). One of the consequences of this postmodern cultural shift is the degradation of widely accepted coming of age rites of passage (Deegan 1989, 1998; Mahdi, Christopher, and Meade 1996). For instance, Arnett $(1998 ; 2001)$ suggests that intangible coming of age markers, such as accepting responsibility and deciding on one's own beliefs, have tempered the importance of tangible rites of passage, such as completing one's education and getting married. A primary goal of traditional rites of passage is to establish a relatively permanent identity status change; however, as Firat and Shultz (1997) state, postmodernism "encourages the experiencing of many different ways of being, not conforming or committing only to a single one" (p. 190). Thus, the postmodern marketplace liberates consumers from choosing a single selfidentity. In line with this view, it is not surprising that young women in postmodern consumer societies are in a potentially prolonged liminal state. At what point is a child considered an adult? Further, is "adult" even a suitable identity status for which to strive? In the wake of extended liminality between childhood and adulthood, the question emerges of how consumption might stimulate or stifle coming of age identity projects among contemporary girls.

The purpose of this paper is to explore the symbolic connections between coming of age liminality and identity-oriented consumption practices in postmodern American culture. First, I review literature on liminality and identity development, focusing on contemporary adolescent consumers in postmodern culture. Next, I outline the methodology of the study, which follows a unique qualitative approach including 42 female participants' identity narratives and corresponding identity collages for each of three discrete life stages (e.g., early adolescent, late adolescent, adult). Based on the data, I identify five areas in which liminality breeds tension in identity development: finding balance (tension between chaos and organization), expressing individuality 
(tension between uniqueness and conformity), asserting independence (tension between autonomy and reliance), managing self-control (tension between restraint and indulgence), and developing human agency (tension between choice and chance). Findings suggest that consumption practices embedded within coming of age milestones help young girls negotiate the paradoxical tensions present in the liminal stage between childhood and adulthood. Finally, I discuss the ways in which marketers might leverage liminality to support consumption-oriented identity exploration among adolescents.

\section{COMING OF AGE LIMINALITY AND IDENTITY DEVELOPMENT}

Traditional rites of passage provide young people with a distinct transition from one status to another and help define their identities, their social roles, and their personal boundaries (van Gennep 1960; Eliade 1958; Mahdi et al. 1996). In the case of adolescence, young people begin their transition into adulthood by both symbolically and physically separating from their childhood roles through a series of transformative experiences. Upon completing the liminal phase, participants enter the third stage, the reincorporation stage, in which participants emerge with a new status represented through their attitudes, values, behaviors, and identities. For instance, the Satere-Mawe tribe of Brazil marks the transformation from boy to warrior by a ceremony in which young boys must place their hands inside woven gloves filled with bullet ants-an insect whose painful sting is thirty times worse than a bee sting. Each boy must keep his hands inside the gloves for ten minutes as fellow initiates and elders dance with him. This process is repeated nineteen more times in the following months and upon completion, the boy is considered a warrior in the eyes of his tribe (National Geographic 2007).

From a consumer culture perspective, it is not enough to identify the liminal occasions of adolescence, like one's first car (e.g., representing freedom and independence) or one's first love (e.g., representing sexual exploration and emotional involvement; Collins 2003). We must understand how young people react to their liminal experiences-how liminality shapes personality, human agency, and introspection (Thomassen 2009)—and how consumption practices help or hinder this process. As Rutter (2001) states, there is "a need to focus on the process of negotiation of life transitions, and not just their occurrence or the behavioral outcome that follows" (p. 7). In consumer research, several studies touch on the concepts of rites of passage and liminality (Belk, Sherry, and Wallendorf 1988; Celsi, Rose, and Leigh 1993; Banister and Hogg 2006; Landzelius 2001; Pavia and Mason 2004; Schau, Gilly, and Wolfinbarger 2009), but only a few studies to date explicitly investigate liminal consumption practices and processes (Cody and Lawlor 2011; Noble and Walker 1998; Schouten 1991). In particular, Cody and Lawlor (2011) examine the liminal consumption of tweens and suggest that marketing segmentation strategies that rely upon boundary conditions (e.g., age limits) are inherently flawed, given individuals' reluctance to commit to a single social category.

Liminality encourages consumers to continually redefine themselves. The question then remains, how do consumers exhibit identity-driven consumption when their identity is in a state of liminal flux? Consumer products represent meaning-laden signs and symbols attached to contemporary rites of passage (Mick 1986; Rook 1985). Previous marketing research suggests that consumer preferences and identities are likely to emerge and transform in response to major life events and transitions such as getting married or retiring (Andreasen 1985; Gentry, Kennedy, Paul, and Hill 1995; Mehta and Belk 1991; Mergenhagen 1995; Noble and Walker 1997, Schouten 1991, 
Schewe and Balazs 1992). As Moschis (2007) points out, consumers gradually change their identities to fit adopted or anticipated roles and engage in activities consistent with those roles. In particular, the modern marketplace has revolutionized female gender role expectations. For instance, the median age of first marriage among American women has increased by $21 \%$ between 1980 and 2012, from 22.0 to 26.6, respectively (Arroyo, Payne, Brown, and Manning 2013). The cultural shift may be due a wider acceptance of premarital sex, cohabitation and birth control, and that young women also feel less rushed to have babies due to assisted reproductive technology (Arnett 2004). In highly industrialized societies such as America, the age at which coming of age transitions takes place varies, as does the nature of the transitions (Delany 1995). In a culture in which it is nearly impossible to escape the marketplace (Kozinets 2002), consumption inevitably plays a symbolic role in the identity development process (Belk 1988; Berger and Heath 2007; Kleine, Kleine, and Allen 1995; Levy 1999; McCracken 1986; Schau and Gilly 2003; Schau, Gilly, Wolfinbarger 2009; Schouten 1991; Solomon 1983).

Previous research largely focuses on major life transitions from childhood to adolescence (e.g., puberty; Sprinthall and Collins 1988; Simmons, Burgeson, and Reef 1988) or the primary transitions associated with achieving adult status (e.g., marriage, having a child; Smith 2003). In contrast, my focus is on the liminal period of time between childhood and adulthood and the role of consumption practices in identity development. The important distinction here is between identity progress and identity attainment. In other words, I am more interested in the progress toward adult status than the attainment of adult status itself.

\section{METHODOLOGY}

Here I present the methodological approach for data collection and analysis. Building on liminality as a theoretical base, I employ a unique qualitative research approach to better understand how young girls construct their identities through consumption practices. Namely, I examine self-identity collages and accompanying written narratives for three discrete life stages: early adolescence, late adolescence, and adulthood. Following previous visually driven research (Belk, Ger, and Askegaard 2003; Chaplin and John 2005; Collier and Collier 1999), participants were asked to answer the general question of "Who Am I?" through creating identity collages and accompanying written narrative summaries for each of three discrete life stages: early adolescence, late adolescence, and adulthood. Given that this study is focused on the progression and transitional nature of rite of passages experienced from childhood through adulthood, the targeted participant population includes female late adolescents, who are in the prime of liminality wedged between the teenage high school years and the forthcoming adult life stage. This study focuses specifically on young women given recent changes in traditional female gender roles in the United States (Arroyo, Payne, Brown, and Manning 2013). Participants were recruited from business classes at a large public university in the Southeastern United States.

Participants were asked to perform a creative task consisting of two parts: 1) constructing three self-identity collages and 2) writing an accompanying narrative summary for each collage. First, each participant was asked to create three collages: one representing her past early adolescent self-concept (i.e., 5 years ago), one representing her current late adolescent selfconcept (i.e., current age), and one representing her future, adult self-concept (i.e., 5 years in the future). The collages were limited to $81 / 2 \times 11$ inches, but they could be made using any medium (e.g., ClipArt, magazine cut outs, photographs). Figure 1 provides collage examples. Second, 
Figure 1. Identity Collage Examples

Participant: GINA

Early Adolescence (Age 15)

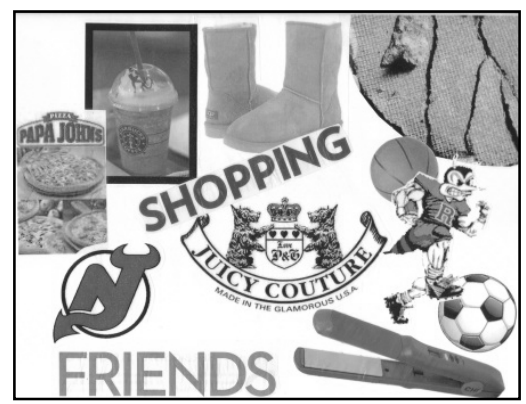

Participant: JILLIAN

Early Adolescence (Age 15)

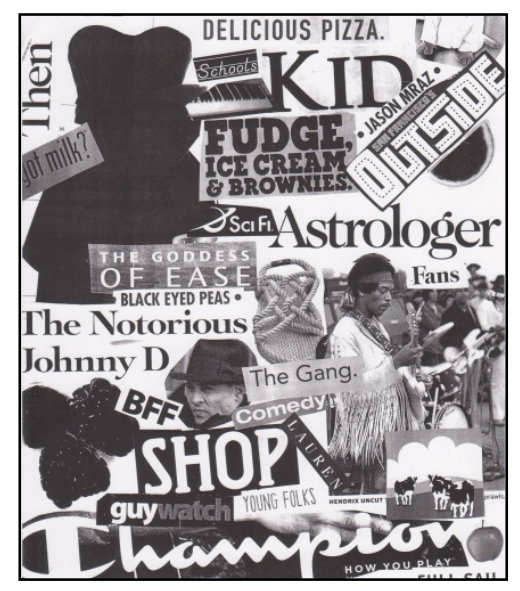

Late Adolescence (Age 20)

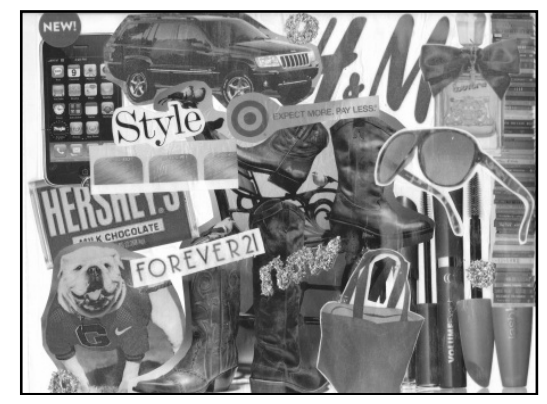

Adulthood (Age 25)

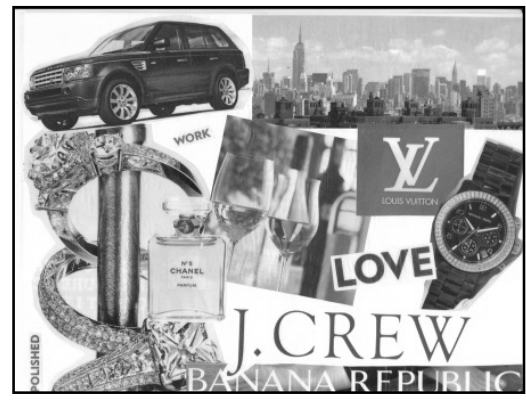

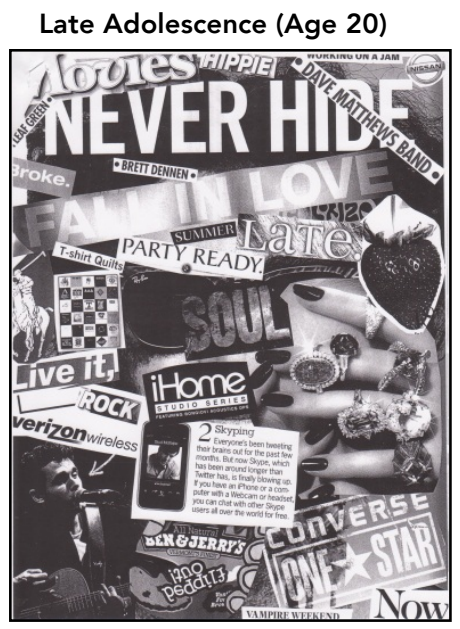

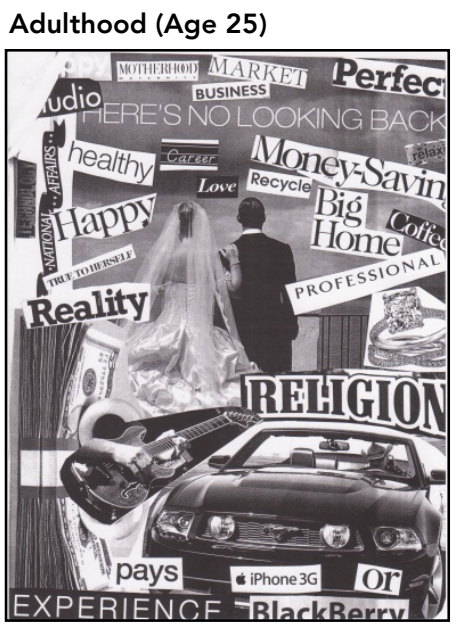

\section{Participant: KIMMIE}

Early Adolescence (Age 16)

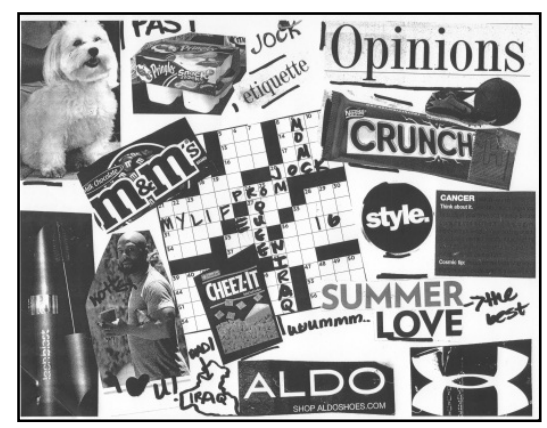

Late Adolescence (Age 21)

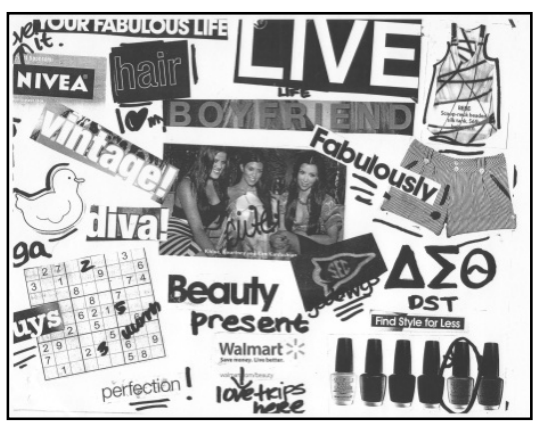

Adulthood (Age 26)

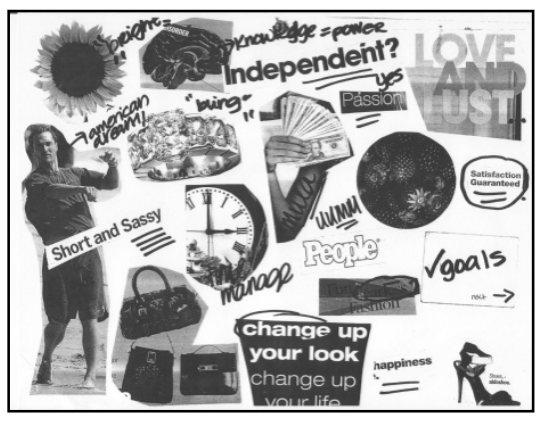


each participant wrote a short narrative reflection summary about each collage, resulting in three collages and accompanying summaries per participant. The method was designed to capture the transitional, liminal state in which adolescents operate by collecting collages and narratives reflecting each participant's past, present, and future self.

In total, forty-two college females (87\% Caucasian, 12\% African American, 1\% Asian American) produced self-identity collages and corresponding written identity narratives. Thus, a total of 126 self-identity collages and corresponding narrative summaries were produced. The participants ranged in age from 20-years-old to 23-years-old, with an average of 21-years-old. Therefore, on average, the past collages and written narratives represented the participants' 16year-old selves and the future collages and written narratives represented the participants' 26year-old selves. To ensure anonymity, each participant was assigned a pseudonym.

I employed a hermeneutical approach of interpretation, as outlined by Thompson (1997). The data were first analyzed within participant, accounting for transition within each participant's collages and accompanying narrative. Then, the collages and narratives were compared across participants by life stage group. Therefore, interpretation of the data reciprocally develops a conceptual framework. After analyzing the narrative summaries and identity collages, general themes were identified and further developed regarding persistent features of liminality and related coming of age consumption practices. Data analysis was deemed complete when a conceptually dense conceptual framework emerged.

\section{FINDINGS}

By contextualizing written narratives through the structural elements of identity collages, this study exposes adolescents' conflicting coming of age identity processes and the ways in which market-mediated milestones move young people through the adolescent stage of liminality. Themes emerged suggesting that the liminality between childhood and adulthood is characterized by five identity tasks in which paradoxical tensions arise: finding balance (tension between chaos and organization), expressing individuality (tension between uniqueness and conformity), asserting independence (tension between autonomy and reliance), managing self-control (tension between restraint and indulgence), and developing human agency (tension between choice and chance). Table 1 provides the framework of liminal identity tensions identified in this study. Coming of age in postmodern consumer culture involves negotiating these tensions through consumptionoriented benchmarks, which I term "market-mediated milestones." Market-mediated milestones refer to consumption-oriented incremental changes that can transform an individual's selfconception. Although in the overall scheme of life, market-mediated milestones may seem trivial, to a young consumer navigating the liminal phase between child and adult, these subordinate milestones are culturally meaningful and central to their identity exploration processes. For example, in and of itself, the American ritual of prom is unlikely to alter one's life trajectory in any significant way, but in the context of adolescent identity development, prom might be viewed as a momentous and meaningful milestone, imbued with consumption practices and symbolic meanings. The data suggest that today's youth use market-mediated milestones to negotiate the paradoxical tensions embedded within the liminal period between childhood and adulthood. Market-mediated milestones are transformative for conceptions of the self, as represented through symbolic consumption. In contrast to the traditional Van Gennupian conceptualization of rites of passage, market-mediated milestones do not necessarily mark a major transition from one social 
Table 1. Framework of Liminal Identity Tensions in Adolescence

\begin{tabular}{|c|c|c|c|}
\hline \multirow{3}{*}{$\begin{array}{l}\text { Basic Identity } \\
\text { Task } \\
\text { Finding } \\
\text { Balance }\end{array}$} & \multirow{3}{*}{$\begin{array}{l}\text { Brief Description } \\
\text { This identity task } \\
\text { concerns an } \\
\text { adolescent's ability to } \\
\text { manage stress and } \\
\text { create stability on her } \\
\text { own life. }\end{array}$} & \multicolumn{2}{|c|}{ Underlying Tensions } \\
\hline & & $\mathrm{CHAOS}$ & ORGANIZATION \\
\hline & & $\begin{array}{l}\text { - Out of control } \\
\text { - Inability to manage stress } \\
\text { - Free-spirited; "live it up" } \\
\text { - Resistance to the organized, } \\
\text { "routine" daily life }\end{array}$ & $\begin{array}{l}\text { - Stability } \\
\text { - Having it all together } \\
\text { - Stress-free and relaxing } \\
\text { - Managing responsibilities }\end{array}$ \\
\hline \multirow{2}{*}{$\begin{array}{l}\text { Expressing } \\
\text { Individuality }\end{array}$} & \multirow[b]{2}{*}{$\begin{array}{l}\text { This identity task } \\
\text { concerns an } \\
\text { adolescent's goal of } \\
\text { conveying her own } \\
\text { distinctive character } \\
\text { traits and qualities. }\end{array}$} & UNIQUENESS & CONFORMITY \\
\hline & & $\begin{array}{l}\text { - Standing out from the } \\
\text { crowd } \\
\text { - Creative; experimental } \\
\text { - "Marching to the beat of } \\
\text { one's } \\
\text { own drum" }\end{array}$ & $\begin{array}{l}\text { - Fitting in with the crowd } \\
\text { - Trend follower } \\
\text { - Compliance with social norms } \\
\text { and expectations }\end{array}$ \\
\hline \multirow{2}{*}{$\begin{array}{l}\text { Asserting } \\
\text { Independence }\end{array}$} & \multirow[b]{2}{*}{$\begin{array}{l}\text { This identity task } \\
\text { concerns an } \\
\text { adolescent's ability to } \\
\text { separate from her } \\
\text { parents and become } \\
\text { self-sufficient. }\end{array}$} & RELIANCE & AUTONOMY \\
\hline & & $\begin{array}{l}\text { - Dependence on others } \\
\text { (e.g., } \\
\text { emotional support, financial } \\
\text { support, transportation) } \\
\text { - Comfort and protection } \\
\text { provided by parents }\end{array}$ & $\begin{array}{l}\text { - Enjoying freedom } \\
\text { - Physically and emotionally } \\
\text { distancing oneself from } \\
\text { parents } \\
\text { - Financial independence }\end{array}$ \\
\hline \multirow{2}{*}{$\begin{array}{l}\text { Managing } \\
\text { Self-Control }\end{array}$} & \multirow{2}{*}{$\begin{array}{l}\text { This identity task } \\
\text { concerns an } \\
\text { adolescent's willpower } \\
\text { over her own actions. }\end{array}$} & INDULGENCE & RESTRAINT \\
\hline & & $\begin{array}{l}\text { - Lacking concern for } \\
\text { consequences } \\
\text { - Frivolous spending, } \\
\text { overeating } \\
\text { - Making mistakes } \\
\end{array}$ & $\begin{array}{l}\text { - Restrictive } \\
\text { - Control over one's urges and } \\
\text { desires } \\
\text { - Concern for consequences }\end{array}$ \\
\hline \multirow{2}{*}{$\begin{array}{l}\text { Developing } \\
\text { Human Agency }\end{array}$} & \multirow[b]{2}{*}{$\begin{array}{l}\text { This identity task } \\
\text { concerns an } \\
\text { adolescent's ability to } \\
\text { make their own free } \\
\text { choices and affect } \\
\text { their personal } \\
\text { circumstances. }\end{array}$} & CHANCE & CHOICE \\
\hline & & $\begin{array}{l}\text { - Emphasis on external locus } \\
\text { of } \\
\text { control } \\
\text { - Fortuitous, divine } \\
\text { intervention } \\
\text { - "Luck of the draw" }\end{array}$ & $\begin{array}{l}\text { - Emphasis on internal locus of } \\
\text { control } \\
\text { - Power to choose one's own } \\
\text { destiny }\end{array}$ \\
\hline
\end{tabular}

status to another, nor do they follow clearly defined stages (i.e., separation, liminality, and reincorporation; Turner 1987; Van Gennep 1960). Instead, market-mediated milestones represent achievable criteria by which adolescents solidify their adult self-concepts. Overall, the primary contribution of this paper lies in providing a framework of identity tensions which are negotiated through market-mediated milestones. The findings are supported here with illustrative examples from the identity collages and written narratives. While these liminal identity tensions are presented as distinct ideas, it should be noted they are interdependent and highly intermingled. This supports the proposition that the adolescent identity negotiation process is not necessarily linear; rather, market-mediated milestones help adolescents navigate liminality through an organic and incremental coming of age process (see Figure 2). 
Figure 2. Negotiation of Identity Tensions through Market-Mediated Milestones

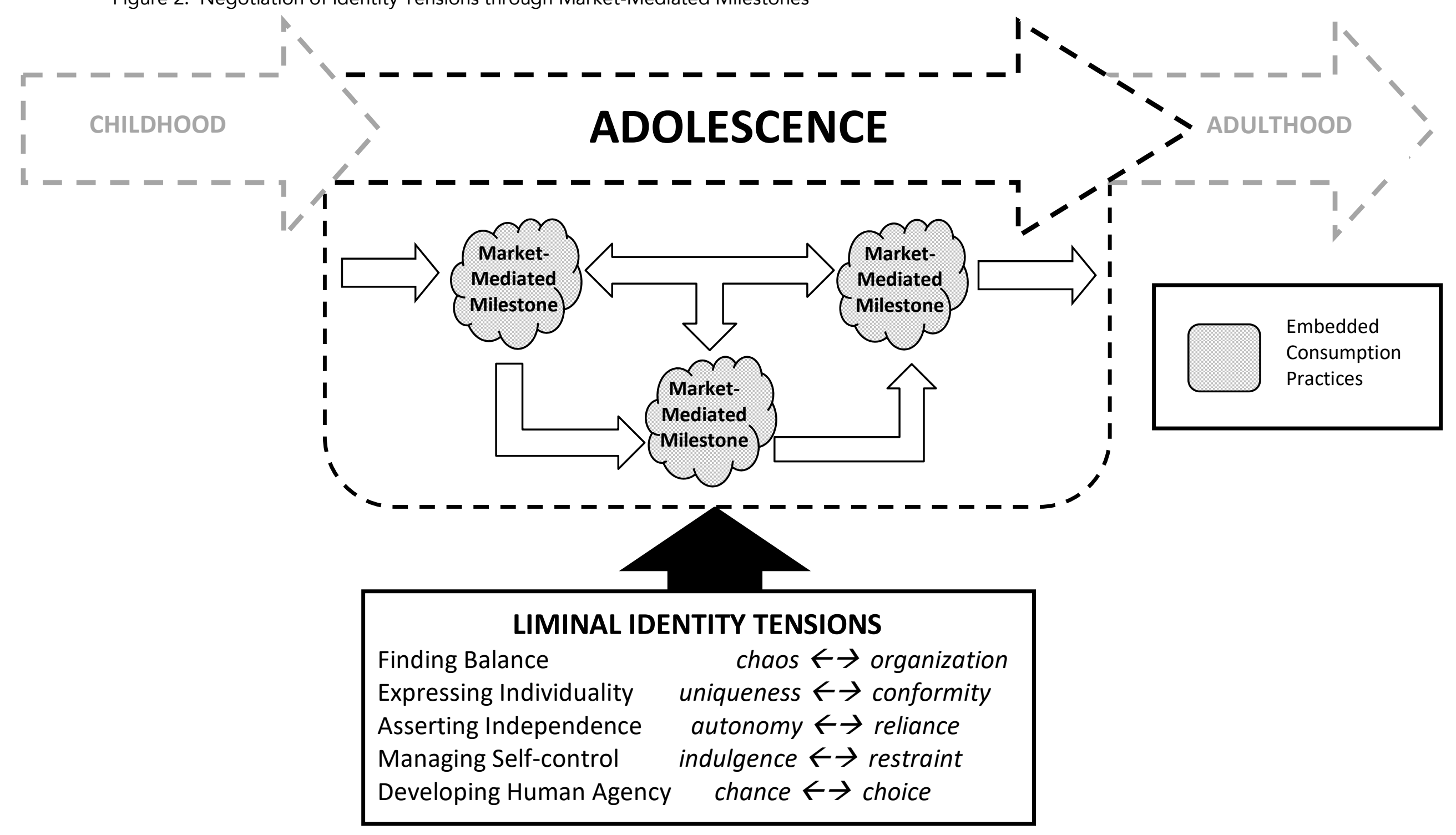




\section{Finding Balance: The Tension between Chaos and Organization}

Finding balance in one's life is a key identity task in the liminal life phase between childhood and adulthood. The data indicate that a tension exists between chaos and organization. Participants suggest that they embrace in the chaos of liminality but desire for more balance, organization, and stability in their lives. Many of the participants intentionally organized the layout of their collages, based upon the level of stress associated with each age.

Jade (age 21, present narrative): Today, I am twenty-one-years old, and my life is a mess. I have no idea where I am going; therefore, my collage is a scrambled mess. I am Alice in Wonderland falling through space. My life currently changes constantly. My life is not simple, but I like it complex.

In Jade's narrative and collage, we can see her negotiating the tension between chaos and organization. She spends time reflecting upon the disorder of her liminal life state but ends with justifying the disordered life stage by stating that she prefers the complexities associated with her current identity. The liminal period between childhood and adulthood is characterized by chaos, stress, and anxiety, yet, a prevailing hope of the organized, balanced serene life waiting in the future. Interestingly, this hope for a structured adult future is almost chaos inducing in the present self. For example, the market-mediated milestones that Laura associates with her future, such as marriage and childbearing, make her more likely to "live it up" in the present.

Laura (age 21, present narrative): I am currently 21 and although I should be focusing more on my future, I am having too good of a time with my friends during my last years of college. The word "SELF" towards the bottom of my collage describes my attitude these days. This is the last time in my life where I can focus on myself, because once I get married and start having kids, my life will not truly be my own anymore.

This "live it up" mentality is represented on Laura's present collage pictures of branded alcohol like SKYY vodka and Malibu Rum and photographs of herself partying with friends. Interestingly, her future identity collage alludes to a sense of pulling herself together (e.g., words like "You've found a new happy place" and "Stronger than ever.")—organizing, balancing, and perfecting all aspects of her life and leaving behind her chaotic adolescent years. Laura's narratives encapsulate the freedom that young consumers feel to enjoy themselves during their coming of age years. They recognize their desire for balance and organization, but they suggest that it comes at the cost of their fun-loving, chaotic, youthful years. The consummate adult future self for which young girls desire is in direct contrast to the chaotic lived experiences which they are not yet willing to forfeit.

The participants' visions of their future selves are represented by the series of marketmediated milestones that will grant them the "balanced life" for which they aspires. The products associated with the market-mediated milestones take on symbolic meaning to represent an exit from the liminal adolescent stage and an entrance into the future organized adult stage. Liminality is characterized by chaos, but young consumers embrace it by dreaming of the tangible goods that might represent their future organized self.

Gina (age 25, future narrative): I included some cutouts of things such as a Blackberry, a Nissan 350Z, and a house. These are just examples of things that represent having my life together, finally. 
The struggle for balance in one's life can also be viewed as a tension between carefree enjoyment and adult responsibilities. Young consumers describe their futures as calculated, wellorganized, and meticulously scheduled. For instance, Kimmie (age 26) includes a clock on her future collage, which she suggests represents time management and balance, and she writes in her future narrative that one of the most dramatic changes she anticipates in her life is an end to her "lively and free-spirited" present self.

\section{Expressing Individuality: The Tension between Uniqueness and Conformity}

Adolescence marks a time in which teenage girls grapple with who they are and how they want to be perceived by others. Evidence in the data suggests that a key tension in liminal identity exists in the realm of individuality, in which a conflict arises between uniqueness and conformity. In other words, young girls struggle between following their own unique life path or conforming to social norms and expectations. For instance, Deanna (age 16, past narrative and collage) indicates that part of her early adolescent identity includes her "signature fragrance" Dolce Gabbana Light Blue, which she wore "so much it makes [her] want to vomit now." Her adolescent sense of self is uniquely wrapped up in her physical appearance, so much so that others might recognize her by smell. However, Heather conforms to the fashion trends of her peers.

Heather (age 16, past narrative): For fashion, I was really into just following the high school trends and wearing whatever is most popular. I loved wearing Abercrombie and Fitch and Hollister, but my style has evolved a lot since the past.

As the participants note, many of their favorite high school fashion brands were considered trendy among their friends, not necessarily trend-setting. Young girls do not want to be perceived as "followers" but they do want to develop as sense of belongingness within their peer group. This tendency to conform to fashion trends persists into adulthood. Fashion brands like J.Crew, Banana Republic, and Ann Taylor were commonly featured on participants' future self-concept collages, suggesting that young people on the threshold of adulthood already expect to adjust their personal brand preferences to match their expectations of adulthood.

Madison (age 26, future narrative): I will probably be wearing more J. Crew and other more sophisticated, conservative brands. CNN and other news channels will probably be of more interest to me at that time. My professional life will probably have me on the go drinking lots of Starbucks and other caffeine-packed snacks.

It is critical to take into account the role of symbolic consumption practices within the liminal stage between childhood and adulthood. Using brands more closely associated with becoming an adult woman mark a key market-mediated milestone among adolescent girls. The data in this study reveal that teenagers tend to follow general trends of their friends in the realm of fashion and accessories; however, the adolescent years provide a pedestal to experiment with creative self-expression through beauty brands and products. In this way, girls pursue a sense of creativity and individualism by experimenting with their physical appearance through beauty regimens (e.g., make-up, hair color) and body modifications (e.g., tattoos, piercings).

Kimmie (age 16, past narrative): I started to show expression through my appearance. I began finding my inner feminine side and began wearing my first real makeup: MASCARA!! My mom let me use hers at first and then finally bought me my own tube of Maybelline Great Lash mascara in the pink bottle - I thought it was the greatest thing ever! 
Consumption and anti-consumption of particular products reflect an emerging self-concept (e.g., makeup and cosmetics reflect femininity and womanly beauty). The participants suggest that wearing make-up is a reflection of their emerging womanhood. Furthermore, they make a point to legitimize the make-up they began using as "real" makeup. These are not the toy cosmetic sets that they played with as children. Interestingly, the participants' future collages include significantly less beauty products than their adolescent collages. Girls in the liminal stage between childhood and adulthood struggle to express their individuality given the tension between uniqueness and conformity. For example, Summer describes how her liminal life stage has provided the opportunity to experiment with her appearance and express her individuality; however, as she transitions into adulthood, she feels the necessity to conform to societal expectations.

Summer (age 21, present narrative): I dyed my hair for the first time my Senior year of high school. It's been every color under the sun: blonde, red, brown, black, even bright pink highlights. Recently, I went back to my "natural" color because I just started applying for internships and need to look professional.

Young girls make adjustments in their appearance to reflect their adult coming of age identities. The uniqueness afforded in the liminal life stage is trumped by the pressures to conform to an adult identity-in Summer's case, a professional businesswoman. It is just as important to examine young girls' resistance to identity expectations, as it is to better understand their compliance toward such expectations. Anti-consumption, or "a resistance to, distaste of, or even resentment of consumption," is symbolically related to self-concept factors (e.g., self-esteem, selfefficacy; Zavestoski 2002, p. 121) and undesired self-states (Hogg, Banister, and Stephenson 2008). According to the data, milestones commonly associated with entering adulthood include entering the workforce, purchasing a home, getting married, and having children. The identity collages suggest that all of these milestones are embedded with consumption practices, which often truncate the importance of the milestone itself. For example, of the 41 unmarried participants, twenty-seven included a diamond ring on their future self collages to represent their expected or hoped-for nuptials; however, many participants suggested that they would buy the ring for themselves if no suitor came along in the 'right' timeframe. Modern girls are conflicted toward the necessity of marriage to express their entrance into adulthood. Market-mediated milestones may feature traditional rites of passage (e.g., marriage) but the embedded symbolic meaning is defined by the individual based on this juggling act between uniqueness and conformity. In other words, each individual consumer, rather than culture as a whole, defines what a milestone means in terms of identity development.

Deanna (age 26, future narrative): In five years, I will be 26. I am nervous about all the change coming up for me, and how I don't know exactly where I will be or what I will be doing in five years. Although my future is unsure, my collage represents what I hope will happen in the coming years. I know I should get married and have kids by the time I'm 30, but who are we kidding, these make believe timelines never work out as planned. Plus, I want to upgrade "Rhonda Honda" to a nice, new Benz for all my hard work, so I can't have babies getting my leather seats all gross right away. I'd also like to travel, learn to be a gourmet cook, have dinner parties, and entertain my friends at my beautiful house with a pool! I'd also like to take up golf. 
Today, young girls in America have more opportunities and options for their futures than past generations. Having a career is not at the cost of having a family and vice versa. There are many different routes toward adulthood, and modern adolescents recognize that they can choose their own unique path. Nonetheless, female consumers still feel innately compelled to pursue traditional gender roles. The struggle between discovering one's own unique path and conforming to social norms and expectations represents a key tension of identity in the liminal stage of adolescence.

\section{Asserting Independence: The Tension between Reliance and Autonomy}

Consumers' lived experiences are embedded in interpersonal relationships (e.g., family, friends, coworkers, teachers, neighbors) throughout the life course. From an identity development perspective, one of the primary tensions in adolescence is the separation-individuation process in which adolescents begin to break away from their parents (Blos 1962; Kroger 1985). In line with this view, evidence in the data suggests that the liminal stage between childhood and adulthood creates a tension between reliance and autonomy in the realm of independence. Adolescents begin to emotionally and physically distance themselves from their parents and guardians, while still maintaining a connection with them. They feel that adolescence is a period of testing limits, breaking rules, and enjoying freedom; however, they remain primarily dependent on the adults in their lives for providing structure, creating financial stability, and offering wisdom. In this study, the participants describe the transitions in their interpersonal relationships and use phrases like "be my own person," "independence is everything," "99\% financially independent," and "free" to describe their coming of age identities.

Deanna (age 16, past narrative): The picture on the bottom right is of my family. My little brother is 8 years younger than me, but we were always very tight. I also have an incredible relationship with my mom and dad. Five years ago, however, I was sixteen, living under their roof, and thought I knew everything. I was a typical selfish teenager who thought the world revolved around me. The girls in the upper left-hand corner were my group of best friends in high school. We called ourselves the A-team to let you in on how cool we thought we were. Haha, but we did have a blast!

Deanna (age 21, present narrative): Now that I am a senior in college, I believe I have done a lot of growing up. While still great friends with my high school group, I came to college and found new best friends and my boyfriend who have been there for me no matter what these past three years.

Deanna (age 26, future narrative): I hope to gain the wisdom my parents have, but I know that in five years I will not be on their level. I think technology will be the future of our world and want to keep as current as I can so I do not end up a dinosaur like my mom and dad.

The previous past, present, and future narratives track the transitions in the participants' relationships. For instance, in contrast to her past teenage identity, Deanna's future self-concept presents a level of respect for her parents, while also recognizing how she will be different from them in order to adapt to a changing technology-driven marketplace. Evidence in the data suggests market-mediated milestones allow adolescent girls to symbolically establish a sense of bounded independence and negotiate the tension between reliance and autonomy. Such 
milestones include earning a driver's license, moving out of the house, and becoming financially independent. These mark formative moments in which young girls actively assert their independence within the liminal stage between childhood and adulthood. Two exemplary marketmediated milestones discussed here are earning a driver's license and obtaining part time employment.

Nearly all of the past identity collages include specific references to driving (e.g., a photograph of a car, a copy of a driver's license, an automobile brand logo). The data suggest that driving represents freedom and independence in the minds of adolescents. Access to a reliable transportation coupled with the prospect of the freedom to drive alone provides young people with a sense of bounded independence. Nonetheless, the independence that accompanies driving is bounded in that parents set the rules regarding how and when their teenage children are allowed to drive; however, teen drivers are required taking on greater responsibilities (e.g., arriving to school on time, paying for gas and car maintenance, abiding by traffic laws). Obtaining a driver's license allows young girls to begin establishing their independence, within the boundaries set forth by their parents. In this way, they begin establishing autonomy from their parents while still relying on them. Furthermore, driving gives teenagers the opportunity to secure part-time work, which lays a foundation for financial independence.

Kiara (age 16, past narrative): Five years ago, I was a student in High School. I had just gone to my junior prom and was reaching my senior year. I had just gotten my license, which is every 16-year-old's dream-to be independent, have your own mode of transportation, and be free. I had just been given my first job as a cashier at Taco Bell, making $\$ 6.25 /$ hour. I thought it was the greatest thing in the world. I got to eat all the Taco Bell I wanted and was getting paid to do so. I have always been a frugal spender; still, I thoroughly enjoyed going to the mall on weekend and going through the sales rack.

Importantly, teenagers' first jobs mark a crucial market-mediated milestone in which young people step beyond the role of consumer and enter the position of employee for the first time in their lives. They feel a new sense of freedom, responsibility, and independence. Furthermore, according to the data, earning a paycheck spurs other market-mediated milestones (e.g., opening a bank account, getting a credit card). Teens who work part-time begin establishing their bounded independence through exhibiting financial responsibility; however, they may still rely on their parents or guardians for providing most essentials. For instance, Madison (age 16, past narrative) states that in high school, she "loved Rock and Republic jeans, and tended to buy nicer clothes since [she] was still under [her] parents' roof." However, as Madison's (age 21, present narrative) reflects on her current shopping habits, she notes that she "shop[s] at Target a lot for cheaper clothing since [she is] on a tight budget." Learning to manage money and be truly selfsufficient is a slow process that takes place throughout the liminal stage between childhood and adulthood. Young girls oscillate between autonomy and reliance as they separate from their parents and depend more upon themselves. In the pursuit of independence, alternative relationships (e.g., romantic relationships, friendships) and group affiliations (e.g., sororities, athletic teams, faith-based organizations) provide the emotional support and social interaction once provided by their parents. Negotiating the tension between autonomy and reliance is an arduous and often times emotional process. Some market-mediated milestones are rooted in affectively charged experiences (e.g., death of a loved one, first love, parental divorce, loss of virginity). These milestones mark turning points in the adolescent's life in which she must make 
emotionally charged decisions and healthily handle the consequences of potentially traumatic life transitions.

Katie S. (age, past narrative): One really important event that I reflected in my collage was my first "serious" relationship. This helped me grow tremendously and I represented it [on my collage] with a beanie baby angel bear because it was the first gift he gave me when we were together. I think I still have it at home in a shoebox in my closet. I should probably get rid of that when I go home.

Consumption practices help young girls symbolically navigate the emotional experiences on the road toward becoming independent adults. Symbolic consumption or disposition of consumer goods provides a tangible way for young girls to mark their coming of age transitions. For instance, as Katie suggests that her first love is represented by tangible consumer product (e.g., beanie baby bear). Interestingly, she left the bear at her parents' house as she left home for college, symbolically separating herself from this past identity but still having access to it through returning home. She evaluates the experience of her youth and recognizes the urge to discard this particular item that is not representative of her emerging adult identity. As young girls experience the ups and downs of adolescence, they learn to become less dependent on their parents and begin to become more self-reliant.

\section{Managing Self-Control: The Tension between Indulgence and Restraint}

The emerging independence discussed in the previous section leads to a tension in selfcontrol between indulgence and restraint. As young girls establish the capability to make independent marketplace decisions, such as where to shop or dine, they take on responsibility for regulating their behaviors, such as eating, exercising, and spending money. Young consumers' decisions are often directed and regulated by their parents, but as adolescents begin to separate from the adults in their lives, parents leave self-control in the hands of their children. The following narratives reflect the tension between restraint and indulgence throughout the liminal stage of life between childhood and adulthood.

Anna (age 16, past narrative): Looking back at the sports I participated in, which were soccer and basketball, I realize how athletic and active I was then. Now, I am a member of [a local gym], but I have to drag myself to go. I suppose with the freedom of college also came the excuses to not go exercise.

Anna (age 21, present narrative): When I go to Kroger to go grocery shopping, there are certain essentials that I always buy: Ramen noodle coups, Crystal Light Lemonade Packs, and Swedish Fish. The truth has become evident in college that I hate to cook, and with easy-to-make items such as the soups I always eat, this drastically differs from how I used to eat in high school. My mom used to cook every night when I was living at home, but now that I am out by myself, I choose to save time cooking, and spend more time on other activities, such as jewelry-making, shopping, or studying. Unlike my active exercise schedule I had in high school, although I am a member of [a local gym], I have hard time making myself go on a daily schedule.

Anna (age 26, future narrative): When I'm 26, I definitely plan to make my health a priority by actually learning to cook nutritious meals and exercising regularly. I used to be so motivated but over the last few years, I haven't been as committed to living a healthy lifestyle. 
As Anna gained more freedom to make her own decisions, she began to recognize their shortcomings in the realm of self-control. Interestingly, like most of the participants, Anna indicates that her adult self will be better at self-control. Young female consumers believe they have a right to indulge as adolescents because they are planning to be more restrictive as adults. For example, junk food brands (e.g., Cheez-lt, Pringles, Edy's), candy brands (e.g., M\&M's, Sour Patch Kids), and fast food brands (e.g., Taco Bell, McDonald's, Dairy Queen) are clearly represented on the participants' past and present collages but not at all on the future collages, which only reflect healthy lifestyles. The tension of self-control between restraint and indulgence extends beyond food. For example, as the following quote suggests, Kelsey (age 21, present narrative) admits that she has little self-control when it comes to swearing and even recognizes it as one of her self-assessed faults. Nonetheless, she continues to indulge herself in it. Evidence in the data suggests that such self-control "mistakes" represent market-mediated milestones. For instance, Ariel (age 21, present narrative) notes that "gaining the 'Freshman 15' was a turning point that made [her] focus more on exercising and eating right" and Jillian (age 20, present narrative) comments that she "made the mistake of maxing out [her] first credit card" in college and includes the phrase "scrimping and saving" on her collage. The tension between restraint and indulgence is evident in the liminal coming of age period between childhood and adulthood. Adolescents must learn how to assert self-control in the tempting consumer-centric marketplace. Liminality between childhood and adulthood provides a sort of trial and error period in which young girls alternate between restraint and indulgence, seeking the perfect blend of moderation.

\section{Developing Human Agency: The Tension between Chance and Choice}

The fifth and final tension identified by the data alludes to the role of human agency, which views people as capable of making their own choices and constructing their own life trajectories, within personal systems of opportunities and constraints. The liminal tension lies between choice and chance-in other words, young girls oscillate between believing that one has the power to choose her own destiny or that destiny is a result of fortuitous chance beyond the individual's power.

Jade (age 26, future narrative): I hope to have a pretty stable life by then. I want to have a career and live in London. I will be driving a flashy, racecar and living in an awesome loft. I would love to continue traveling the world and collecting treasures and memories, learning about other cultures. I want to still be able to have a good time and not to take myself too seriously. I will have a golden retriever, and maybe I will have more than one. I will still be active in charities and I hope to be posh, collecting great works of art. But most importantly, I want to be happy. I want to be happy. I want to have good relationships and be on my way to making a family. I want to be in love and have all the pieces of my life falling into place. Knowing me though, my life will still be a complete mess.

Jade has great plans for her future self beyond her liminal years and a clear picture of which market-mediated milestones she needs to achieve in order to reach her goals; however, she almost entirely discounts the likelihood of achieving these milestones by suggesting that she will self-sabotage her future plans. In contrast, many participants suggest that their futures lie in the hands of a greater divine being based on a particular faith or set of spiritual beliefs. Tension between choice and chance is evident here in that a young girl might plan her future but states 
that it is "in God's hands"; therefore, she partially surrenders control of her life course to the chance of a divine being. Some participants present their adult identities and associated consumption practices as certainties (e.g., "I will get married," "I am going to live in New York") whereas others present them as possibilities (e.g., "I might drive a BMW," "I hope to own a home"). Thus, an interesting contradiction exists both within and across participants, not in what they say about their future adult identities but in how they say it. The way in which young girls discuss their futures provides insight into the agentic forces perceived to be at work. In the data, girls who speak in certainties about their future market-mediated milestones imply that they are in control of their own destinies, whereas girls who present their futures in terms of possibilities suggest that other forces may be at work. Importantly, speaking in certainties may be crippling for a young girls' self-concept. For instance, Julie (age 25, future collage) includes a quote on her future collage that states, "What screws us up most in life is the picture in our head of how it should be." Along the life course, external factors may redirect one's direction. By speaking in possibilities, instead of certainties, young girls embrace the liminal tension between control and chance; thus, they follow the postmodern trend of pursuing various identities.

\section{DISCUSSION}

The findings of this study make both theoretical and practical contributions to the existing literature. Few studies to date have challenged traditions views of rites of passage in the postmodern era, particularly as they pertain to young consumers' coming of age identity processes. This study unpacks the underlying tensions that characterize the liminal adolescent stage of life. Drawing from theory on liminality and adolescent identity development, the findings show that incremental market-mediated milestones serve as platforms by which young consumers might negotiate these identity tensions throughout adolescence.

This study makes a theoretical contribution in re-conceptualizing how scholars perceive the role of rites of passage in contemporary consumer culture. In contrast to the rigidly structured Van Gennepian view of rites of passage, market-mediated milestones serve as incremental, individualized markers along the way toward becoming an adult. Thus, coming of age identity development is a result of constant negotiation of the tensions embedded within adolescent liminality through market-mediated milestones. Furthermore, although there is some evidence that individuals in their teens and twenties agree on what signifies adult status (Arnett 1998, 2000, 2001, 2004), this study suggests that coming of age in postmodern America is an incremental, individualized, market-oriented process.

One of the primary differences between traditional rites of passage and market-mediated milestones lies in the nature of identity. Traditional rite of passage perspectives suggest that consumers traverse a stage of liminality in order to take on a relatively permanent, well-defined identity status. In contemporary culture, identity status change is liquid in nature. An individual may revert to a previous status or may quickly transition to yet another new status, given that identity is a result of constantly conflicting tensions. For instance, as the findings suggest, a young

girl is not automatically considered an independent adult as soon as she moves out of her parents' house. She continues to struggle with the tension between separation from her parents and reliance on them. Thus, "becoming an adult" is in many ways an antiquated concept. Even in postmodern American culture, we see clear age group markers: birth, childhood, adolescence, adulthood, old age, death; however, in today's society, division of age groups is ambiguous and 
timing of coming of age market-mediated milestones is less static. In other words, the boundaries between age categories have increasingly blurred, as too have the temporal rightness of life milestones. The social institutions upon which traditional rites of passage are based have changed; therefore, our conceptions of what rites of passage are today should change as well.

Another primary difference between traditional rites of passage and market-mediated milestones involves the embedded marketplace products, which represent meaning-laden signs and symbols (Levy 1999; Mick 1986; Rook 1985). Such symbols are fundamental elements in the broader context of rites of passage and in the meanings of specific acts within each rite. Traditionally, the meaning of signs and symbols are decided upon by a particular subculture; however, the proposed conceptualization of market-mediated milestones suggests that the interpretation of these signs and symbols are highly individualized. The consumption practices embedded within market-mediated milestones are customized to the individual and therefore the symbolic significance of such consumption is open to interpretation. For example, for one young girl, wearing "real" makeup for the first time may represent conforming to gender expectation as a woman, whereas another girl may view it as an opportunity to express her uniqueness and creative identity. Meaningful marketplace objects contribute to building the coming of age identity of the individual adolescent. This supports the postmodern perspective that "everything can be taken and assembled according to the free choice of the individual" (Cova 1999, p. 72).

The liminality of adolescence allows young female consumers "to play with the factors of sociocultural experience" (Turner 1985, p. 236). In this way, liminality provides the freedom to explore various identities, challenge sociocultural norms, and adapt to changes. From a marketing perspective, we often tout customer loyalty as the preeminent goal. However, the wonderful thing about young adolescent consumers is their adaptability to change and their willingness to embrace new experiences. They may not remain loyal to a few single brands; rather, they dabble in a multitude of brands as they attempt to figure out who they are and what their marketplace preferences might be. Thus, the liminality of adolescence becomes a primary source of marketplace experimentation. Marketing has the power to leverage this liminality-to encourage young girls to explore a multitude of identity options and even create new social norms. However, this should be done with great care for the consumer's well-being. In a sense, adolescence represents a road with multiple identity directions. Adulthood represents the selection and commitment to a single one. From a marketing perspective, encouraging consumers not to commit to a single pathway may be profitable. Consumers will be more likely to try new products, embrace changes in technology, and seek novel consumption experiences. Marketing practitioners may consider creating new market-mediated milestones for which consumers to mark their identity transitions. In liminality, the adolescent girl is forced to think about the established social norms as she prepares to re-enter that structure as an adult woman. The liminal adolescent learns what is expected of them while they are between the fixed states of childhood and adulthood. Furthermore, as identity tensions arise throughout adolescence, young consumers turn to the marketplace to help themselves adapt. Advertising and marketing practices targeted toward adolescents should be careful not to take advantage of young consumers during the tumult of their liminal teenage years. 


\section{FUTURE DIRECTIONS}

For young consumers, coming of age liminality represents a period meaningful identity exploration. This study represents the first step toward understanding coming of age marketmediated milestones and the identity tensions embedded within the liminal adolescent stage of life. Future research should further examine how such milestones play a role in identity development beyond the adolescent stage. In postmodern consumer culture, are consumers in a constant state of liminality in which they are continually assessing their identities? If so, how might the marketplace support consumers' identity projects? Furthermore, although this study focuses primarily on adolescent girls, that is not to say that boys do not experience similar coming of age processes. Future studies should explore differences across consumers based on various demographic variables such as gender, age (e.g., early adolescents versus older adults), socioeconomic status, religion, and geographic location. A limitation of this study is its focus on American consumer culture alone. Future research should take a cross-cultural approach to examine differences between countries. Given the transitional nature of identity over time, a longitudinal study is an imperative next step toward understanding how adolescents negotiate their identities through market-mediated milestones and to exploring the role of identity tensions coming of age processes. Finally, in the context of rites of passage, resisting a culturally expected milestone may result in self-identity discord or interpersonal struggles. The concept of anticonsumption begs the question, why might a young girl choose not to partake in modern marketmediated milestone, or rite of passage? Furthermore, what influence does skipping or missing a teenage rite of passage have on a young girl's emerging adult identity? Future research should explore anti-consumption of market-mediate milestones. 


\section{REFERENCES}

Andreasen, A. R. (1985). Consumer Responses to Dissatisfaction in Loose Monopolies. Journal of Consumer Research, 12(2), 135-141.

Arnett, J. J. (1998). Learning to Stand Alone: The Contemporary American Transition to Adulthood in Cultural and Historical Context. Human Development, 41(5/6), 295-315.

Arnett, J. J. (2000). Adolescence and Emerging Adulthood: A Cultural Approach. Upper Saddle River, NJ: Prentice Hall.

Arnett, J. J. (2001). Conceptions of the Transition to Adulthood: Perspectives from Adolescence Through Midlife. Journal of Adult Development, 8(2), 133-143.

Arnett, J. J. (2004). Emerging Adulthood: The Winding Road from the Late Teens through the Twenties. New York, NY: Oxford University Press.

Arnett, J. J., \& Tanner, J. L. (2006). Emerging Adults in America: Coming of Age in the 21st Century. Washington, DC: American Psychological Association Press.

Arroyo, J., Payne, K. K., Brown, S. L., \& Manning, W. D. (2012). Crossover in Median Age at First Marriage and First Birth: Thirty Years of Change (FP-13-06). National Center for Family \& Marriage Research.

Banister, E. N., \& Hogg, M. K. (2006). Experiencing Motherhood: The Importance of Possible Selves to New Mothers. Advances in Consumer Research, 33(1), 343-344.

Belk, R. W. (1988). Possessions and the Extended Self. Journal of Consumer Research, 15(2), 139168.

Belk, R. W., Ger, G. I., \& Askegaard, S. r. (2003). The Fire of Desire: A Multisited Inquiry into Consumer Passion. Journal of Consumer Research, 30(3), 326-351.

Berger, J., \& Heath, C. (2007). Where Consumers Diverge from Others: Identity Signaling and Product Domains. Journal of Consumer Research, 34(2), 121-134.

Blos, P. (1962). On Adolescence. New York, NY: The Free Press.

Celsi, R. L., Rose, R. L., \& Leigh, T. W. (1993). An Exploration of High-Risk Leisure Consumption through Skydiving. Journal of Consumer Research, 20(1), 1-23.

Chaplin, L. N., \& John, D. R. (2005). The Development of Self-Brand Connections in Children and Adolescents. Journal of Consumer Research, 32(1), 119-129.

Cody, K., \& Lawlor, K. (2011). On the Borderline: Exploring Liminal Consumption and the Negotiation of Threshold Selves. Marketing Theory, 11(2), 207-228.

Collier Jr., J., \& Collier, M. (1986). Visual Anthropology: Photography as a Research Method.

Albuquerque, NM: University of New Mexico Press.

Collins, W. A. (2003). More than Myth: The Developmental Significance of Romantic Relationships during Adolescence. Journal of Research on Adolescence, 13(1), 1-24.

Cova, B. (1999). From Marketing to Societing: When the Link Is More Important Than the Thing. In D. Brownlie, M. Saran, R. Wensley \& R. Whittington (Eds.), Rethinking Marketing: Towards Critical Marketing Accountings (pp. 64-83). Thousand Oaks, CA: SAGE Publications Ltd.

Deegan, M. J. (1989). American Ritual Dramas: Social Rules and Cultural Meanings. New York: Greenwood Press.

Deegan, M. J. (1998). The American Ritual Tapestry: Social Rules and Cultural Meanings. Westport, CT: Greenwood Press.

Delaney, C. H. (1995). Rites of Passage in Adolescence. Adolescence, 30(120), 891-897.

Eliade, M. (1958). Rites and Symbols of Initiation. New York, NY: Harper. 
Firat, A. F., \& Shultz II, C. J. (1997). From Segmentation to Fragmentation. European Journal of Marketing Theory, 31(3).

Gentry, J. W., Kennedy, P. F., Paul, C., \& Hill, R. P. (1995). Family transitions during grief:

Discontinuities in household consumption patterns. Journal of Business Research, 34(1), 67-79.

Hogg, M. K., \& Banister, E. N. (2001). Dislikes, Distastes and the Undesired Self: Conceptualising and Exploring the Role of the Undesired End State in Consumer Experience. Journal of Marketing Management, 17, 73-104.

Kleine, S. S., \& Baker, S. M. (2004). An Integrative Review of Material Possession Attachment. Academy of Marketing Science Review, 1(1), 1-39.

Kozinets, R. V. (2002). Can Consumers Escape the Market? Emancipatory Illuminations from Burning Man. Journal of Consumer Research, 29(1), 20-38.

Kroger, J. (1985). Separation-Individuation and Ego Identity Status in New Zealand University Students. Journal of Youth and Adolescence, 14(2), 133-147.

Landzelius, K. M. (2001). Charged Artifacts and the Detonation of Liminality. Journal of Material Culture, 6(3), 323-344.

Levy, S. J. (1999). Brands, Consumers, Symbols, \& Research: Sidney J. Levy on Marketing. Thousand Oaks, CA: Sage Publications, Inc.

Mahdi, L. C., Christopher, N. G., \& Meade, M. (Eds.). (1996). Crossroads: The Quest for Contemporary Rites Of Passage. Peru, IL: Open Court Publishing.

McCracken, G. (1986). Culture and Consumption: A Theoretical Account of the Structure and Movement of the Cultural Meaning of Consumer Goods. Journal of Consumer Research, 13(1), 71 84.

Mehta, R., \& Belk, R. W. (1991). Artifacts, Identity, and Transition: Favorite Possessions of Indians and Indian Immigrants to the United States. The Journal of Consumer Research, 17(4), 398-411. Mergenhagen, P. M. (1995). Targeting Transitions: Marketing to Consumers during Life Changes. Ithaca, NY: American Demographics.

Mick, D. G. (1986). Consumer Research and Semiotics: Exploring the Morphology of Signs, Symbols, and Significance. Journal of Consumer Research, 13(2), 196-213.

Moschis, G. P. (2007). Life Course Perspectives on Consumer Behavior. Journal of the Academy of Marketing Science, 35(2), 295-307.

Noble, C. H., \& Walker, B. A. (1997). Exploring the Relationships among Liminal Transitions, Symbolic Consumption, and the Extended Self. Psychology \& Marketing, 14(1), 29-47.

Pavia, T. M., \& Mason, M. J. (2004). The Reflexive Relationship between Consumer Behavior and Adaptive Coping. Journal of Consumer Research, 31(2), 441-454.

Rook, D. W. (1985). The ritual dimension of consumer behavior. The Journal of Consumer Research, 12(3), 251-264.

Rutter, M. (2001). Pathways from Childhood to Adult Life. In E. Taylor \& J. Green (Eds.), Research and innovation on the road to modern child psychiatry: Classic paper by Professor Sir Michael Rutter. Glasgow, UK: The Royal College of Psychiatrists.

Schau, H. J., \& Gilly, M. C. (2003). We Are What We Post? Self-Presentation in Personal Web Space. Journal of Consumer Research, 30(3), 385-404.

Schau, H. J., Gilly, M. C., \& Wolfinbarger, M. (2009). Consumer Identity Renaissance: The Resurgence of Identity-Inspired Consumption in Retirement. Journal of Consumer Research, 36(2), 255-276.

Schewe, C. D., \& Balazs, A. L. (1992). Role Transitions in Older Adults: A Marketing Opportunity. 
Psychology and Marketing, 9(2), 85-99.

Schouten, J. W. (Writer) (1991). Selves in Transition: Symbolic Consumption in Personal Rites of Passage and Identity Reconstruction [Article], Journal of Consumer Research: Journal of Consumer Research, Inc.

Simmons, R. G., Burgeson, R., \& Reese, M. J. (1988). Cumulative change at entry to adolescence. In M. R. Gunnar \& W. A. Collins (Eds.), Development during the transition to adolescence (Vol. 21, pp. 123-150). Hillsdale, NJ: Lawrence Erlbaum Associates, Inc.

Smith, T. W. (2003, March). Coming of Age in 21st Century America: Public Attitudes towards the Importance and Timing of Transitions to Adulthood National Opinion Research Center.

Solomon, M. R. (1983). The Role of Products as Social Stimuli: A Symbolic Interactionism

Perspective. The Journal of Consumer Research, 10(3), 319-329.

Sprinthall, N. A., \& Collins, W. A. (1988). Adolescent Psychology: A Developmental View. New

York, NY: Crown Publishing Group/Random House.

Thomassen, B. (2009). The Uses and Meanings of Liminality. International Political Anthropology, 2(1), 5-27.

Thompson, C. J. (1997). Interpreting Consumers: A Hermeneutical Framework for Deriving Marketing Insights from the Texts of Consumers' Consumption Stories. Journal of Marketing Research, 34(4), 438-455.

Turkle, S. (1998). Identity Crisis. In V. J. Vitanza (Ed.), Cyber.Reader. Needham Heights: Allyn \& Bacon.

Turner, V. (1987). Betwixt and Between: The Liminal Period in Rites of Passage. In L. C. Mahdi, S. Foster \& M. Little (Eds.), Betwixt and between: Patterns of masculine and feminine initiation (pp. 319). Peru, IL: Open Court Publishing Company.

Turner, V. W. (1985). On the Edge of the Bush. Tucson, AZ: University of Arizona Press. Van Gennep, A. (1960). The Rites of Passage. Chicago, IL: University of Chicago Press.

Zavestoski, S. (2002). The Social-Psychological Bases of Anticonsumption Attitudes. Psychology and Marketing, 19(2), 149-165. 